\title{
Microstructure and Texture of Hydrostatic Extrusion Deformed Ni Single Crystals and Polycrystal
}

\author{
D. Jakubowska, ${ }^{1}$ J. Zdunek, ${ }^{1}$ M. Kulczyk, ${ }^{2}$ J. Mizera, ${ }^{1}$ and K. J. Kurzydłowski ${ }^{1}$ \\ ${ }^{1}$ Materials Science and Engineering Faculty, Warsaw University of Technology, Woloska 141, 02-507 Warsaw, Poland \\ ${ }^{2}$ Institute of High Pressure Physics (Unipress), Polish Academy of Sciences, 01-142 Warsaw, Poland \\ Correspondence should be addressed to D. Jakubowska; djakubowska@inmat.pw.edu.pl
}

Received 3 July 2015; Revised 18 August 2015; Accepted 23 August 2015

Academic Editor: Ying Li

Copyright (c) 2015 D. Jakubowska et al. This is an open access article distributed under the Creative Commons Attribution License, which permits unrestricted use, distribution, and reproduction in any medium, provided the original work is properly cited.

\begin{abstract}
The differences in the microstructure and texture of two Ni single crystals, with different initial orientations $(\langle 100\rangle$ and $\langle 110\rangle)$, and of polycrystalline nickel, before and after severe plastic deformation (SPD) produced by hydrostatic extrusion (HE), have been investigated. The crystals were deformed by a two-step HE process with a total deformation value of $\varepsilon=1.2$. The global texture, mechanical properties, and microstructure were examined after the deformation. In every investigated sample, the presence of $\langle 111\rangle$ fibre texture was noted, while the starting orientation of a $\langle 100\rangle \mathrm{Ni}$ single crystal was preserved in $50 \%$ of the volume. The results obtained were compared with the relevant literature data.
\end{abstract}

\section{Introduction}

The strength of materials can be increased by forming obstacles to the movement of dislocations, which may be other dislocations, grain boundaries, or the particles of a second phase. One of the ways to strengthen materials is grain refinement through the use of severe plastic deformation methods. In order to better the understanding of deformation textures in polycrystalline nickel, some research has already been carried out on Ni single crystals. Nickel single crystals and polycrystals were mostly deformed by equal channel angular pressing (ECAP) [1-4]. So far, limited investigations have been conducted on hydrostatic extrusion (HE) of Ni single crystals [5] and polycrystals [6]. Moreover, the evolution of microstructure and fibre texture during the hydrostatic extrusion process has been studied on polycrystalline materials [7-11]. The effect of the initial orientation of the material on its subsequent texture and microstructure is not sufficiently clear. This work is intended to complement these studies.

An overview of the literature data indicates that texture formation during extrusion and drawing processes in metals and alloys with an FCC crystal system leads to the creation of $\langle 111\rangle$ and $\langle 100\rangle$ fibre texture. Their proportions in the overall texture depend on, among other factors, the type of deformation [12] and their location in the sample [1, 13] $(\langle 111\rangle$ fibre is dominant in the centre and $\langle 100\rangle$ fibre near the surface of the wire). The proportion of each fibre after extrusion or drawing is decided mainly by the initial orientation; it depends on whether the polycrystal (random) or single crystals with different initial orientations are being deformed.

The goal of this study is to observe the changes in the texture after hydroextrusion of nickel single crystals with different initial orientations and to compare them with the texture changes of polycrystalline nickel undergoing exactly the same deformations in the process of hydroextrusion. During the discussion of the results, a comparison of similar experiments on other single crystals and polycrystals of the FCC crystal system has also been included. This study is focused on the evolution of the microstructure and texture of $\mathrm{Ni}$ single crystals and polycrystal during plastic deformation realized by hydrostatic extrusion. Two Ni single crystals with different starting orientations $(\langle 100\rangle$ and $\langle 110\rangle)$, as well as polycrystalline Ni material, have been examined during a two-step HE process that achieves a total true strain of $\varepsilon=$ 1.2. Only the results for $\mathrm{Ni}$ single crystals, after an HE process with a different total true strain value, have been presented before [5]. In this study, the authors wanted to investigate 


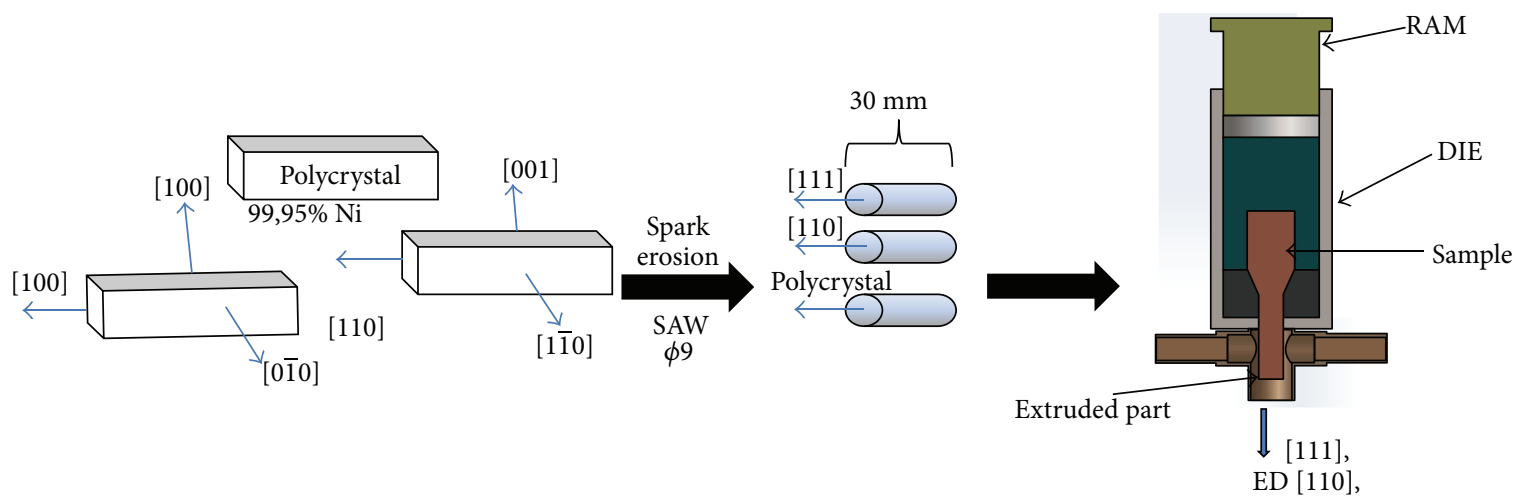

FIGURE 1: Schematic representation of the experiment process.

whether the differences would be noticeable during the same deformation of a single crystal and polycrystal.

\section{Material and Experiment}

Polycrystalline nickel of $99.95 \%$ purity, with a grain size of $10.6 \mu \mathrm{m}$, and two Ni single crystals were investigated. Figure 1 shows schematically the sample preparation for extrusion and the two single crystals' orientation before the deformation. The samples were cylindrical in shape and were cut out along the main crystallographic axes $(\langle 110\rangle$ and $\langle 100\rangle)$ of the single crystals using a spark erosion saw. The thin foils for Transmission Electron Microscopy (TEM) analysis were cut out from cross sections of the samples and prepared by applying the standard technique of electrolytic polishing using Struers apparatus.

The HE process was carried out in two steps (from $\phi 9 \mathrm{~mm}$ to $\phi 7 \mathrm{~mm}$ and then to $\phi 5 \mathrm{~mm}$ ). The total strain of the extruded wires can be calculated by the following equation:

$$
\varepsilon=2 \ln \frac{d_{0}}{d},
$$

where $\varepsilon$ indicates the true strain of the extruded single crystal nickel wires; $d_{0}$ and $d$ denote the diameters of the undeformed $(\phi 9 \mathrm{~mm})$ and extruded wires, respectively. All investigations were conducted on cross sections parallel to the extrusion direction. Changes of the mechanical properties were observed by measuring the microhardness of the initial states and those after deformation using the Vickers method. The microstructure after HE was examined in thin films of the material (specially prepared for TEM), using a Hitachi S5500 SEM/STEM, and the local texture was determined by the EBSD measurement (Hitachi SU70 SEM). The global texture of the materials was analysed by the X-ray diffraction method, using a Bruker D8 DISCOVER powder diffractometer equipped with a $\mathrm{Cr} \mathrm{X}$-ray source.

\section{Results and Discussion}

Figure 2 compares the microhardness of the two $\langle 100\rangle$ and $\langle 110\rangle \mathrm{Ni}$ single crystals and polycrystalline Ni in both the initial state and the state after HE. The microstructure of all the

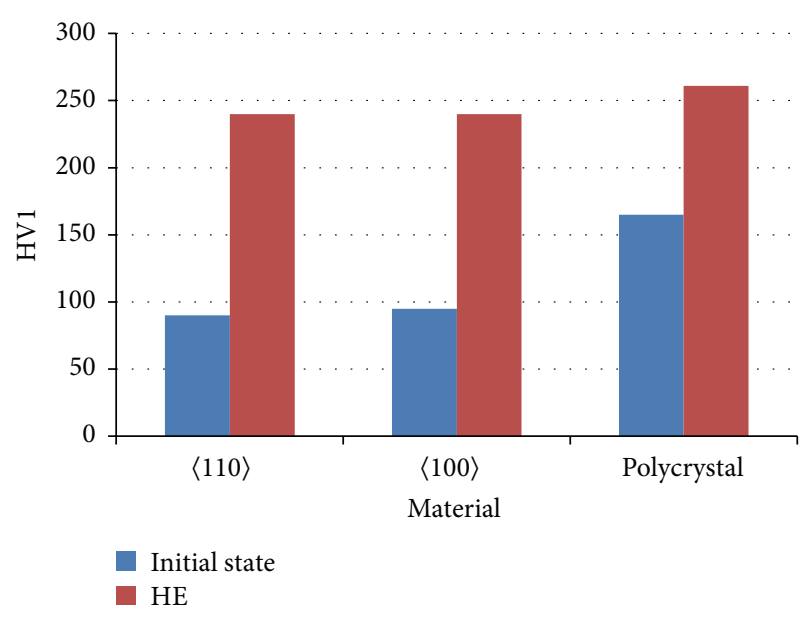

FIGURE 2: Comparison of the microhardness of polycrystalline $\mathrm{Ni}$ and the two $\langle 110\rangle$ and $\langle 100\rangle$ single crystals in the initial state and after $\operatorname{HE} \varepsilon=1.2$.

deformed samples is typical for materials with high stacking fault energy (SFE). It is evident from the micrographs shown in Figure 3 that the density of dislocations is very high inside and near the grains. The grain boundaries are not well defined due to the high dislocation density. The TEM observations allowed the average grain size $\left(d_{\text {eq }}\right)$ to be determined.

The average subgrain parameter of deformed single crystals with the initial orientation of $\langle 110\rangle$ and $\langle 100\rangle$ amounted to $0.21 \mu \mathrm{m}$ and $0.18 \mu \mathrm{m}$, respectively, whereas for polycrystalline $\mathrm{Ni} 99.95 \%$ it was $0.2 \mu \mathrm{m}$. All of these examinations were carried out on a surface perpendicular to the extrusion direction (ED).

The global texture was measured by the X-ray diffraction method, for the initial and deformed states of the polycrystalline nickel. Those investigations showed increased tangling of the fibre texture after HE. The volume fraction of its components is shown in Table 1. Pole figures of the deformed materials show the differential volume fraction of the two components, $\langle 111\rangle$ and $\langle 100\rangle$, for both single crystals and polycrystalline material; see Figure 4 . These results indicate that the $\langle 110\rangle$ initial orientation breaks up entirely during the hydrostatic extrusion process, where large portions of the 


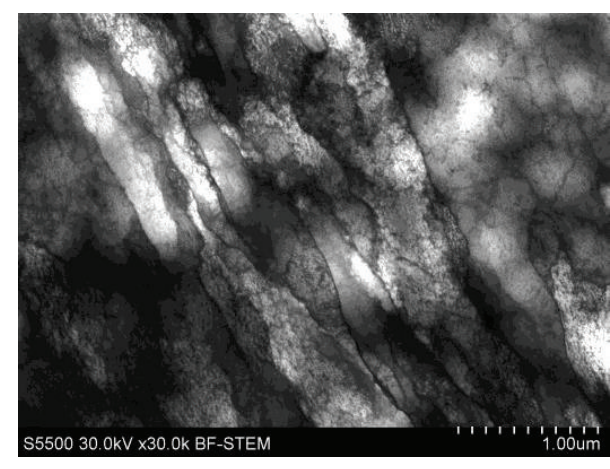

(a)

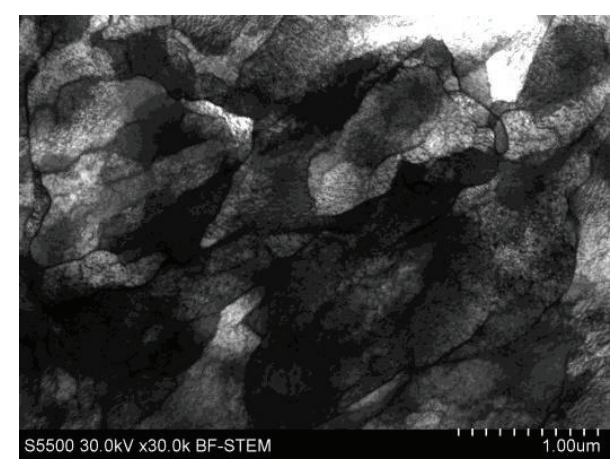

(b)
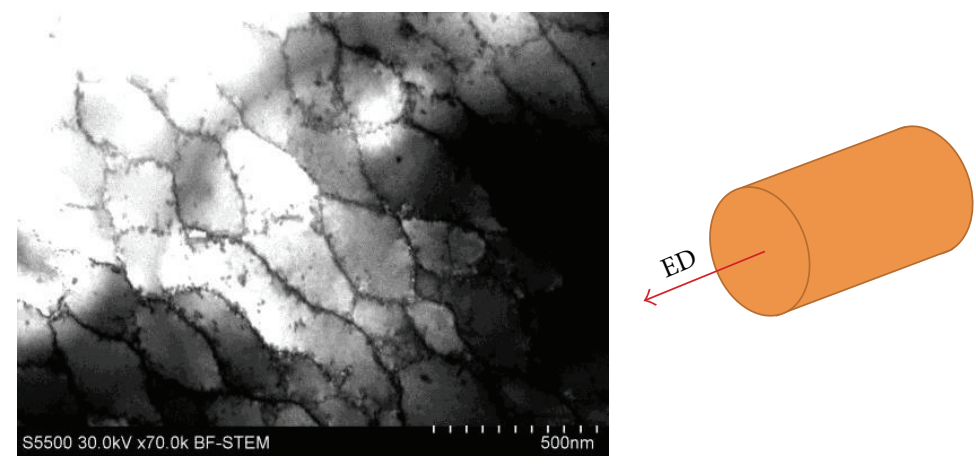

(c)

FIGURE 3: Microstructure after HE with $\varepsilon=1.2$ of initial Ni single crystal $\langle 110\rangle$ (a), $\langle 100\rangle$ (b), and polycrystal (c).

TABLE 1: Results of quantitative texture measurements in $\langle 110\rangle$ and $\langle 100\rangle \mathrm{Ni}$ crystals and $99.95 \% \mathrm{Ni}$ alloy after $\varepsilon=1.2$.

\begin{tabular}{lc}
\hline Initial texture/(orientation) & $\begin{array}{c}\mathrm{HE} e=1.17 \\
\text { (\%vol.) }\end{array}$ \\
\hline Polycrystal & $\mathrm{Ni}$ \\
$\mathrm{Ni}$ & \\
$\langle 100\rangle 41 \%$ & $\langle\mathbf{1 1 1}\rangle 45 \%$ \\
$\langle 111\rangle 13 \%$ & $\langle 100\rangle 41 \%$ \\
$\langle 710\rangle 9 \%$ & \\
Single crystal & $\langle 100\rangle 51 \%$ \\
$\langle 100\rangle$ & $\langle\mathbf{1 1 1}\rangle 17 \%$ \\
$\langle 110\rangle$ & $\langle\mathbf{1 1 1}\rangle 40 \%$ \\
\hline
\end{tabular}

extruded sample have been located close to a $\langle 111\rangle$ fibre. For all deformed samples, both single crystals and polycrystalline nickel, the presence of $\langle 111\rangle$ fibre in the texture is observed. The fibre character of the texture can be proved by the Orientation Distribution Functions (ODFs) calculated for the deformed materials (Figure 5).

3.1. $\langle 110\rangle$ Single Crystal. The initial orientation of the $\langle 110\rangle$ single crystal appears to be unstable during the processes of extrusion and drawing, which has been confirmed in other papers $[5,9]$. These results apply not only to nickel, but also to other single crystals with a FCC system [14]. After a deformation of $\varepsilon=1.2$, a total disappearance of this component occurs, with a $\langle 111\rangle$ component appearing in roughly $40 \%$ of the volume of the material. The complete lack of a $\langle 100\rangle$ component and the presence of large amounts of random components should also be noted. However, after a deformation that was twice as large [5], the $\langle 111\rangle$ component was still dominant (roughly $60 \%$ of the volume), and the presence of the $\langle 100\rangle$ component became evident (roughly $30 \%$ of the volume). At this point, only small amounts of random components were found.

3.2. $\langle 100\rangle$ Single Crystal. The initial orientation of a $\langle 100\rangle$ single crystal appeared to be stable; after a deformation of $\varepsilon=$ 1.2 , roughly $50 \%$ of the volume remained in this orientation. In addition, the $\langle 111\rangle$ component was found in about $20 \%$ of the volume. The above results correspond well with results obtained during extrusion or drawing of other $\langle 100\rangle$ single crystals, or metals with a FCC system, for example, $\mathrm{Cu}$ [15] and $\mathrm{Al}$ [14]. These researchers noted variable amounts of $\langle 111\rangle$ and $\langle 100\rangle$ components, depending on the metal, which has been connected with the influence of SFE, and the size of the deformation. A similar tendency has been observed by Chen et al. [15], when they deformed monocrystalline $\mathrm{Cu}$ of the same initial $\langle 100\rangle$ orientation. These results indicated that the $\langle 100\rangle$ component forms only with higher degrees of deformation.

3.3. Comparison of $\langle 110\rangle$ and $\langle 100\rangle$. Comparison of the two initial orientations of the single crystals deformed by 


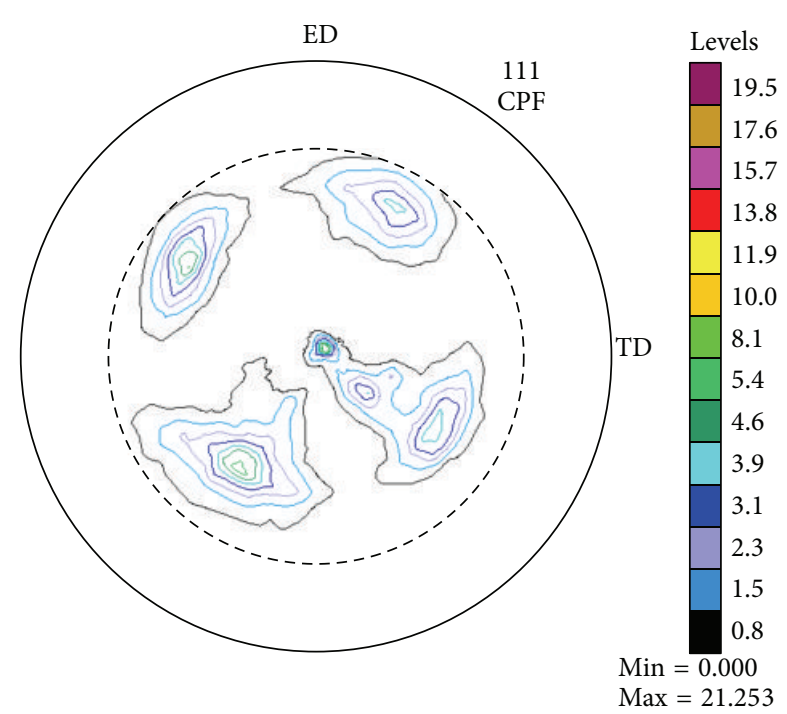

(a)

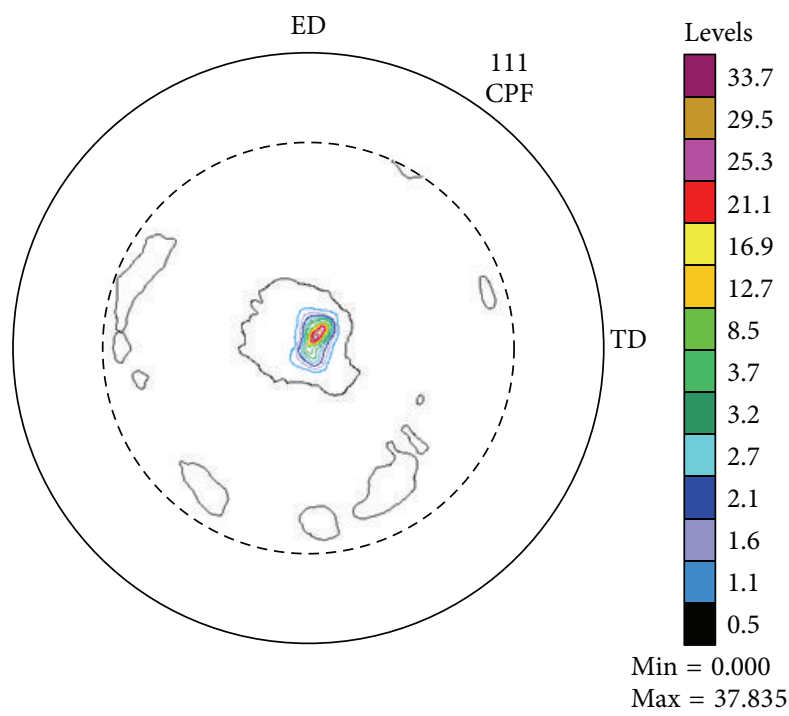

(b)

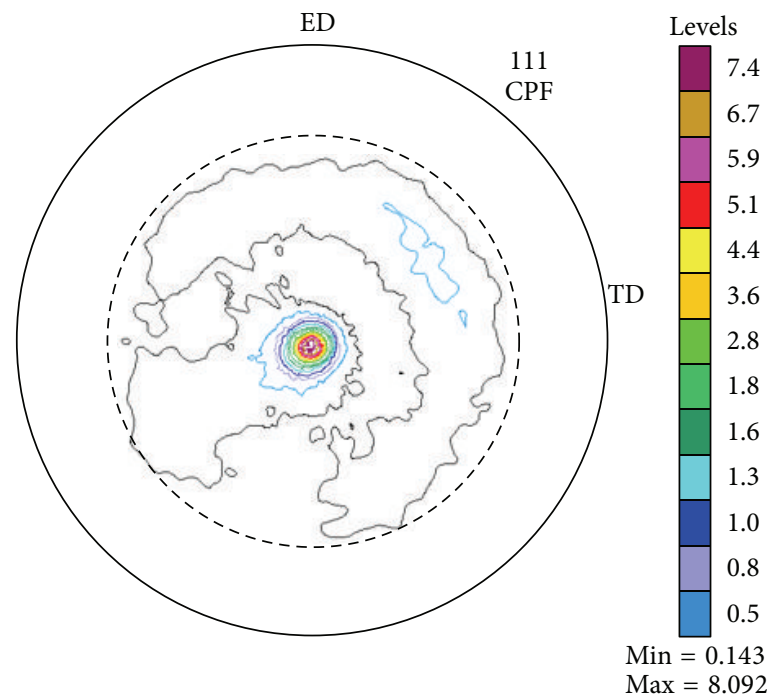

(c)

Figure 4: $\{111\}$ pole figures determined experimentally for $\langle 100\rangle$ (a) and $\langle 110\rangle$ (b) Ni single crystals and Ni polycrystal (c) deformed to $\varepsilon=1.2$.

hydrostatic extrusion shows that after a deformation of $\varepsilon=$ 1.2 the $\langle 110\rangle$ component is unstable, since it disappears completely, while the $\langle 100\rangle$ component appears to be stable and was present in $50 \%$ of the volume of the sample after exactly the same deformation. This component is also present in a large $(30 \%)$ volume in a deformed single crystal with $\langle 110\rangle$ initial orientation, after $\varepsilon=2.4$ [5].

3.4. Comparison of Single Crystals with a Polycrystal. Comparing deformed nickel single crystals (having $\langle 110\rangle$ and $\langle 100\rangle$ initial orientation) with polycrystalline nickel shows that presence of the $\langle 111\rangle$ and $\langle 100\rangle$ components varies between them, depending on the initial texture/orientation and the degree of deformation. Their common attribute is the lack of the $\langle 110\rangle$ component after the deformation. Similar to the single crystals, an increased degree of deformation in polycrystals fosters the increased presence of the strong and stable $\langle 111\rangle$ component. The effect on microstructure and texture of $\langle 111\rangle$ and $\langle 110\rangle \mathrm{Ni}$ single crystals after $\mathrm{HE} \varepsilon=2.4$ has been examined previously [5]. The authors found that hydrostatic extrusion ( $\mathrm{HE} \varepsilon=2.4$ ) applied on the investigated single crystals yielded a strongly refined microstructure with an average subgrain diameter of approximately $300 \mathrm{~nm}$. The analysis of the texture and microstructure in the HE-treated 99.5\% Ni with varying degrees of deformation has been taken up by Kulczyk et al. [16]. For all the applied total strain values, they obtained by the $\mathrm{HE}$ process a heterogeneous, submicrometer microstructure. The authors concluded that for a total strain of up to $\varepsilon=1$ the grains are elongated, which is in agreement with the results presented in this study. After $\mathrm{HE} \varepsilon=1.2$, for single crystal and polycrystalline materials alike, elongated grains in the direction of extrusion 


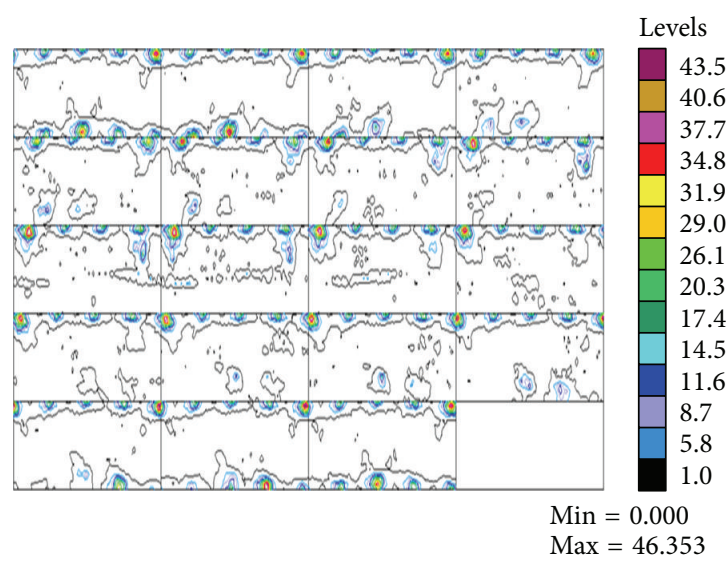

(a)

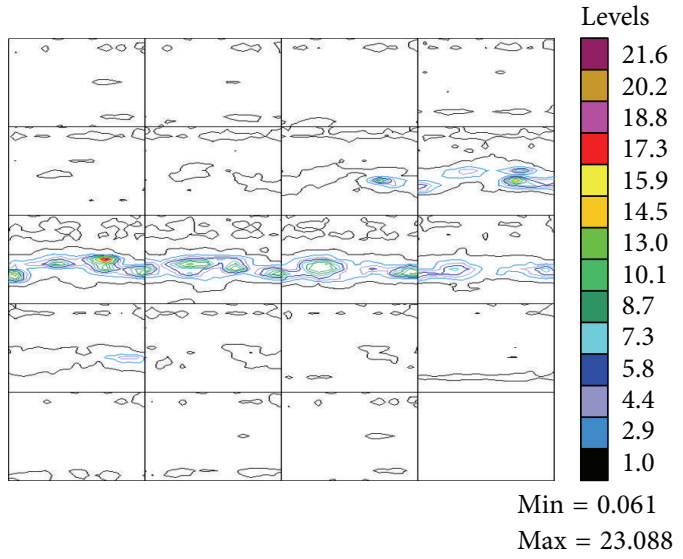

(b)

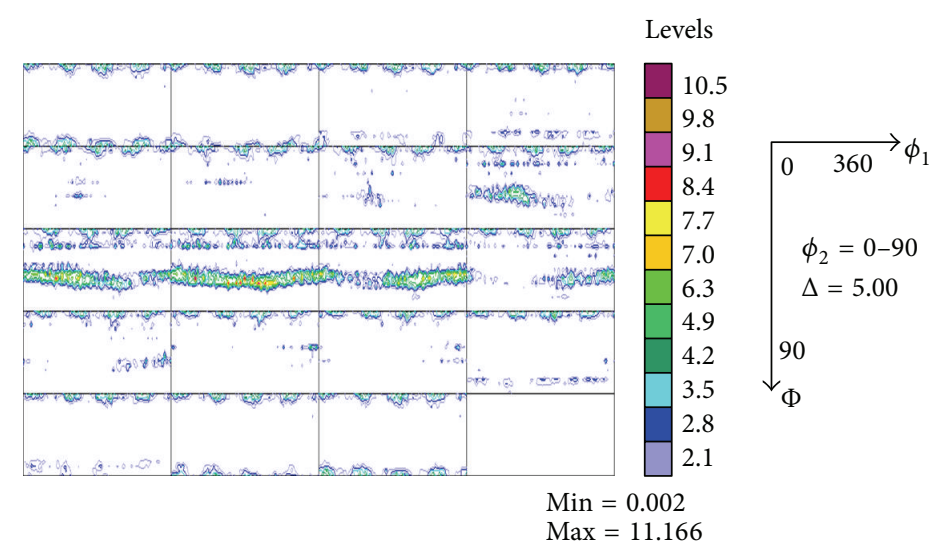

(c)

FIGURE 5: ODFs for constant $\phi_{2}$ value in range of $0-90^{\circ} / 5^{\circ}$ for $\mathrm{Ni}\langle 100\rangle(\mathrm{a}),\langle 110\rangle$ (b), and single crystals and polycrystal (c).

were obtained. These results can also be compared with the studies of Reed and McHargue [14]. They sum up the data on extrusion in FCC poly- and single crystals. The comparison of quantitative texture results obtained in the discussed scientific papers with those shown in the study is presented in Figure 6.

In all of the discussed studies, dominance of the $\langle 111\rangle$ texture component has been observed, regardless of the specified total strain value and initial texture. The exception is HE-treated $\varepsilon=1.2\langle 100\rangle \mathrm{Ni}$ single crystal, where the initial orientation has been maintained in $51 \%$ by volume. The stability of the starting $\langle 100\rangle$ orientation in FCC single crystals after deformation has also been observed in another type of deformation [17]. It can also be noted that by applying higher total strain on $\langle 110\rangle$ single crystals the dominating $\langle 111\rangle$ fibre breaks down to two components: $\langle 100\rangle$ and $\langle 235\rangle$. Mechanical properties, such as yield strength and tensile strength, are affected by texture components. This has been confirmed by the microhardness results obtained in this study. The HE-treated polycrystalline material, with the $\langle 111\rangle$ texture component being the major component present, has the largest $\mathrm{HV}_{0.2}$ value of all the investigated samples.

\section{Conclusions}

Deformation of Ni single crystals and polycrystal by hydrostatic extrusion leads to the formation of fibre texture, which is typical for this process. The initial texture of the polycrystalline material and the initial orientation of the single crystal influence the evolution of the material's texture after its deformation, especially the percentage content of individual components. The degree of deformation also has an impact on the material composition, as the increased deformation fosters the creation of the $\langle 111\rangle$ component. The presence of this strong and stable $\langle 111\rangle$ component is observed regardless of initial texture, accompanied by the $\langle 100\rangle$ component, while the $\langle 110\rangle$ component is not present in any researched case, even when $\langle 110\rangle$ is the initial orientation.

Theoretical studies of the development of deformation texture predict that orientations which have three or more equally stressed slip systems symmetrically arranged about the major flow direction. The presence of a double fiber texture for $\langle 111\rangle$ and $\langle 110\rangle$ fibers has been predicted for FCC materials. Differences in texture might be caused by the temperature and manner of the deformation process, 
$\langle 110\rangle \mathrm{Ni}$ single crystal

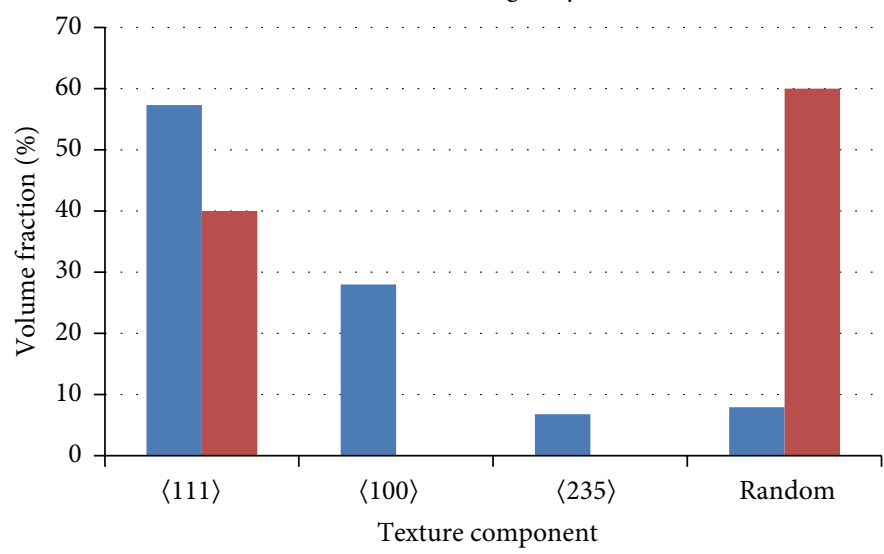

HE $\varepsilon=2.4[5]$

$\mathrm{HE} \varepsilon=1.2$

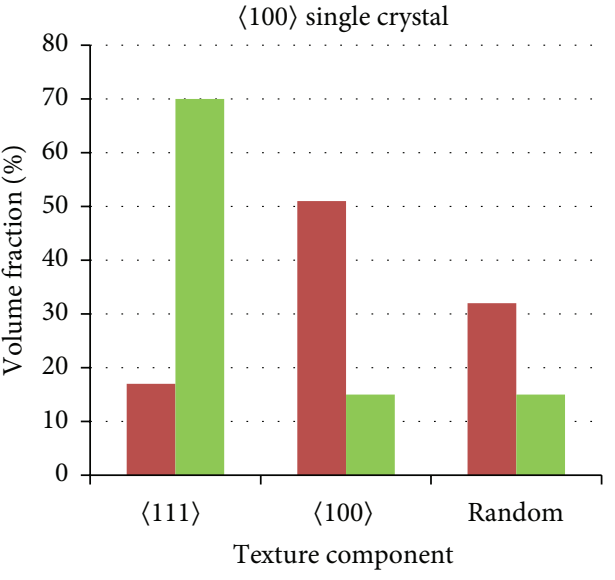

- HE $\varepsilon=1.2$

- Extruded FCC single crystal [8]

(b)

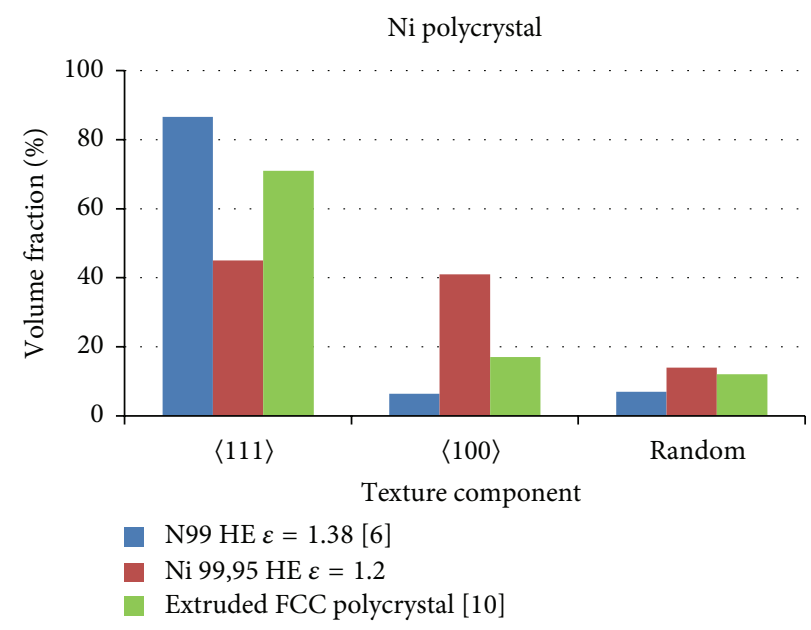

(c)

FIGURE 6: Quantitative texture analysis of single crystals (a) and (b) and polycrystals (c) $[5,6,14]$.

the starting texture of the material, the relative hardening of the active and latent slip systems, and the stacking fault energy (SFE) [18]. The volume fraction of $\langle 100\rangle$ in the texture decreases with increasing SFE. This is related to mechanical twinning. The orientations near $\langle 111\rangle$ will twin first as a result of shear stress on twinning. In metals with high SFE (for pure $\mathrm{NiSFE}=128 \mathrm{~mJ} / \mathrm{m}^{2}$ ), twinning is more difficult, and the $\langle 100\rangle$ component becomes weaker.

\section{Conflict of Interests}

The authors declare that there is no conflict of interests regarding the publication of this paper.

\section{Acknowledgment}

This work was supported in part by the National Centre of Science in Poland, Project no. 2013/09/B/ST8/03754.

\section{References}

[1] W. Skrotzki, L. S. Tóth, B. Klöden, H.-G. Brokmeier, and R. Arruffat-Massion, "Texture after ECAP of a cube-oriented Ni single crystal," Acta Materialia, vol. 56, no. 14, pp. 3439-3449, 2008.

[2] T. Grosdidier, J.-J. Fundenberger, D. Goran et al., "On microstructure and texture heterogeneities in single crystals deformed by equal channel angular extrusion," Scripta Materialia, vol. 59, no. 10, pp. 1087-1090, 2008.

[3] K. Neishi, Z. Horita, and T. G. Langdon, "Grain refinement of pure nickel using equal-channel angular pressing," Materials Science and Engineering A, vol. 325, no. 1-2, pp. 54-58, 2002.

[4] A. Zhilyaev, B. Kim, J. Szpunar, M. Baró, and T. Langdon, "The microstructural characteristics of ultrafine-grained nickel," Materials Science and Engineering A, vol. 391, no. 1-2, pp. 377-389, 2005.

[5] J. Zdunek, J. Mizera, K. Wasik, and K. J. KurzydŁowski, "Microstructural analysis of the $\langle 111\rangle$ and $\langle 110\rangle$ nickel single 
crystals subjected to severe plastic deformation by hydroextrusion," Materials Science and Engineering A, vol. 569, pp. 92-95, 2013.

[6] M. Kulczyk and K. J. Kurzyd, Zastosowanie wyciskania hydrostatycznego do rozdrobnienia ziarna w niklu [Ph.D. thesis], Warsaw University of Technology, Warsaw, Poland, 2007.

[7] P. Bazarnik, B. Romelczyk, M. Kulczyk, and M. Lewandowska, "The strength and ductility of 5483 aluminium alloy processed by various SPD methods," Materials Science Forum, vol. 765, pp. 423-428, 2013.

[8] J. Bohlen, S. B. Yi, J. Swiostek, D. Letzig, H. G. Brokmeier, and K. U. Kainer, "Microstructure and texture development during hydrostatic extrusion of magnesium alloy AZ31," Scripta Materialia, vol. 53, no. 2, pp. 259-264, 2005.

[9] P. Maj, B. Adamczyk-Cieślak, J. Mizera, W. Pachla, and K. J. Kurzydłowski, "Microstructure and mechanical properties of duplex stainless steel subjected to hydrostatic extrusion," Materials Characterization, vol. 93, pp. 110-118, 2014.

[10] S. Zherebtsov, A. Mazur, G. Salishchev, and W. Lojkowski, "Effect of hydrostatic extrusion at $600-700^{\circ} \mathrm{C}$ on the structure and properties of Ti-6Al-4V alloy," Materials Science and Engineering A, vol. 485, no. 1-2, pp. 39-45, 2008.

[11] W. Chrominski, M. Kulczyk, M. Lewandowska, and K. J. Kurzydlowski, "Precipitation strengthening of ultrafine-grained Al-Mg-Si alloy processed by hydrostatic extrusion," Materials Science and Engineering A, vol. 609, pp. 80-87, 2014.

[12] I. J. Beyerlein and L. S. Tóth, "Texture evolution in equalchannel angular extrusion," Progress in Materials Science, vol. 54, no. 4, pp. 427-510, 2009.

[13] H.-P. Lin, T.-S. Ng, J.-C. Kuo, Y.-C. Chen, C.-L. Chen, and S.-X. Ding, "EBSD study on crystallographic texture and microstructure development of cold-rolled FePd alloy," Materials Characterization, vol. 93, pp. 163-172, 2014.

[14] R. E. Reed and C. J. McHargue, "Effect of fabrication method on the texture of aluminum rods," Transactions of the Metallurgical Society of AIME, vol. 242, 1968.

[15] J. Chen, W. Yan, C. X. Liu, R. G. Ding, and X. H. Fan, "Dependence of texture evolution on initial orientation in drawn single crystal copper," Materials Characterization, vol. 62, no. 2, pp. 237-242, 2011.

[16] M. Kulczyk, W. Pachla, A. Mazur et al., "Microstructure and mechanical properties of nickel deformed by hydrostatic extrusion," Materials Science, vol. 23, no. 3, pp. 839-846, 2005.

[17] J. Chen, W. Yan, B. Li, X. Ma, X. Du, and X. Fan, "Microstructure and texture evolution of cold drawing $\langle 110\rangle$ single crystal copper," Science China Technological Sciences, vol. 54, no. 6, pp. 1551-1559, 2011.

[18] H. Wenk, Preferred Orientation in Deformed Metals and Rocks: An Introduction to Modern Texture Analysis, Elsevier, 1985. 

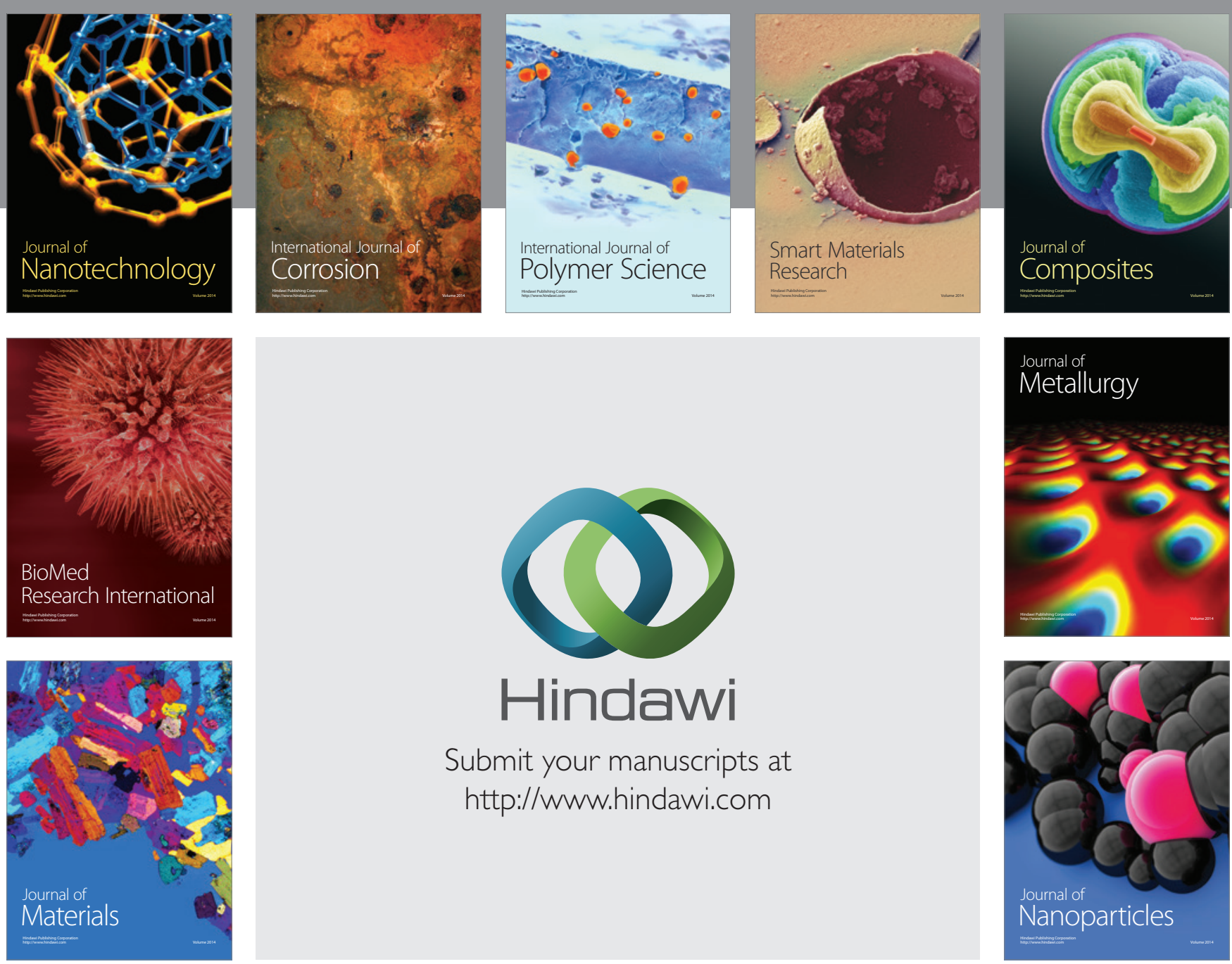

Submit your manuscripts at http://www.hindawi.com
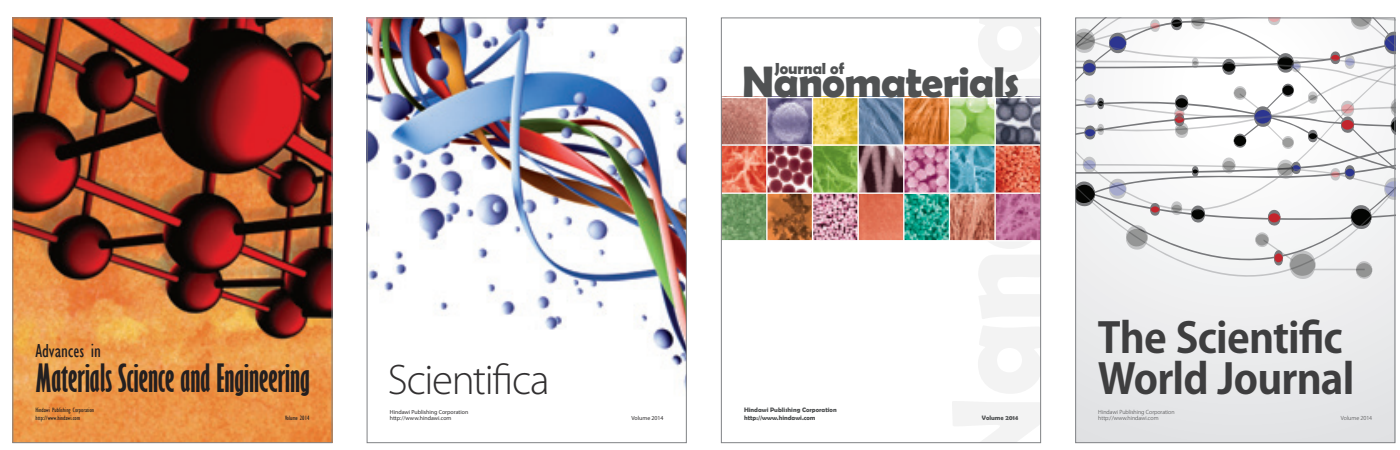

\section{The Scientific World Journal}
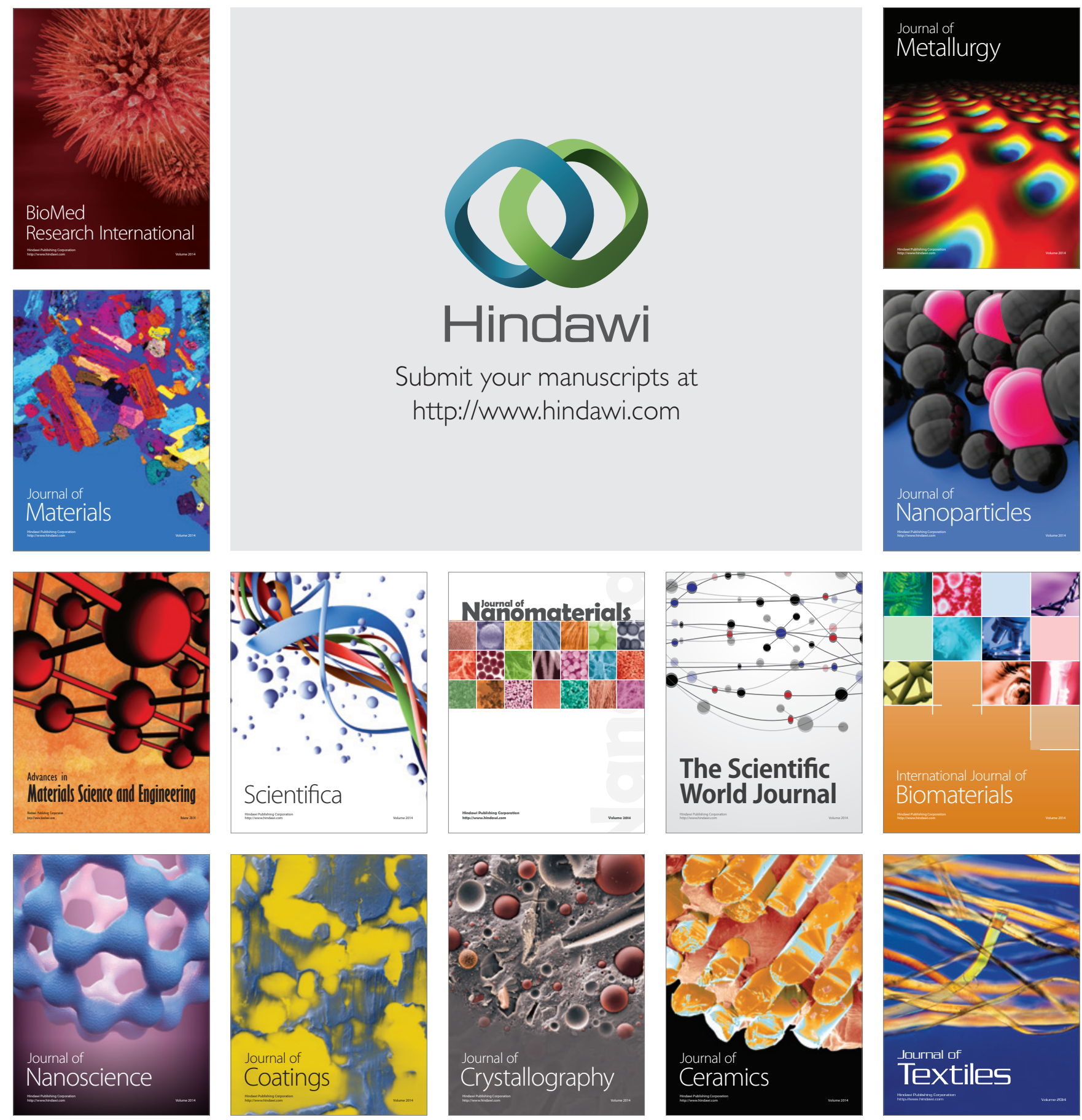